\title{
Mercado de trabalho e perfil profissional: os caminhos da formação e atuação em lazer
}

\author{
Labor market and professional profile: the training routes and leisure activities
}

Mercado laboral y perfil profesional: las rutas de formación y las actividades de ocio

Carla Augusta Nogueira Lima e Santos ${ }^{1}$; Hélder Ferreira ISAYAma ${ }^{2}$

Centro Universitário de SETE Lagoas, UNIFEMM, SETE Lagoas-MG, Brasil

Universidade Federal de Minas Gerais, UFMG, BElo HorizonTE-MG, BraSiL

\begin{abstract}
RESUMO
As configurações do mundo do trabalho são reestruturadas constantemente mediante aspectos históricos, econômicos e tecnológicos. O cenário flexível do mercado de trabalho contemporâneo sugere a formação de profissionais que possuam qualidades para se inserirem no sistema de produção com características cada vez mais líquidas. No campo do lazer, especificamente, espera-se que o profissional possua conhecimentos e habilidades que combinem aspectos técnicos, cognitivos e atitudinais. Para isso, o processo formativo deve buscar a unidade entre teoria e prática estabelecendo laços com a pesquisa e com a formação cultural dos sujeitos. Acreditamos que a formação em lazer calcada nestes princípios pode preparar o profissional de forma a mobilizar seus saberes diante das diversas situações que atravessarão sua trajetória no mundo do trabalho. Palavras-chave: Formação e Atuação. Mercado de Trabalho. Lazer.
\end{abstract}

\begin{abstract}
The settings of the world of work are constantly restructured through historical, economic and technological aspects. The flexible scenario of the contemporary labor market suggests the formation of professionals who have the qualities to be inserted in the system of production with increasingly liquid characteristics. In the field of leisure, specifically, the professional is expected to possess knowledge and skills that combine technical, cognitive and attitudinal aspects. For this, the formative process must seek the unity between theory and practice, establishing links with the research and with the cultural formation of the subjects. We believe that the leisure training based on these principles can prepare the professional in order to mobilize their knowledge in the face of the various situations that will cross their trajectory in the world of work.
\end{abstract}

Keywords: Training and Performance. Labor Market. Recreation.

\section{RESUMEN}

Las configuraciones del mundo del trabajo se reestructuran constantemente mediante aspectos históricos, económicos y tecnológicos. El escenario flexible del mercado de trabajo contemporáneo sugiere la formación de profesionales que posean cualidades para insertarse en el sistema de producción con características cada vez más líquidas. En el campo del ocio, específicamente, se espera que el profesional posea conocimientos y habilidades que combinen aspectos técnicos, cognitivos y actitudinales. Para ello, el proceso formativo debe buscar la unidad entre teoría y práctica estableciendo lazos con la investigación y con la formación cultural de los sujetos. Creemos que la formación en ocio calcada en estos principios puede preparar al profesional para movilizar sus saberes ante las diversas situaciones que atravesarán su trayectoria en el mundo del trabajo.

Palabras clave: Formación y Actuación. Mercado de Trabajo. Ocio.

\footnotetext{
${ }^{1}$ Doutora em Estudos do Lazer pela UFMG. Docente do UNIFEMM. E-mail: carlaugusta@yahoo.com

2 Docente da UFMG e do Programa de Pós-Graduação Interdisciplinar em Estudos do Lazer da UFMG. Coordenador Geral do Programa de Formação, Acompanhamento e Avaliação dos Projetos de Esporte e Lazer da Secretaria Especial do Esporte do Ministério da Cidadania. Editor da Revista Licere. E-mail: helderisayama@yahoo.com.br
} 


\title{
AS CONFIGURAÇÕES DO TRABALHO CONTEMPORÂNEO
}

\begin{abstract}
Fluidez é a qualidade de líquidos e gases. O que distingue dos sólidos é que eles não podem suportar uma força tangencial ou deformante quando imóveis e assim sofrem uma constante mudança de forma quando submetidos a tal tensão (BAUMAN, 2001, p. 168).
\end{abstract}

Bauman (2001) utiliza-se da comparação entre líquidos e sólidos para dialogar, metaforicamente, sobre a contemporaneidade. Ele se apropria do conceito de fluidez para descrever a organização da sociedade com foco nas relações humanas. Os fluidos se movem facilmente e não mantêm uma única forma, diferentemente dos sólidos, que possuem uma estabilidade e são resistentes a mudanças constantes, mesmo quando submetidos a tensões. Assim, os líquidos se deslocam com desenvoltura, fluem, remodelam, esparramam e os sólidos são inertes e rígidos. Dessa forma, os líquidos são associados a mudanças e a estágios de mobilidade e flexibilidade.

Os estudos de Bauman (2001) nos auxiliam na compreensão da transição da modernidade para a contemporaneidade. A primeira é considerada uma fase sólida, por abrigar relações e organizações sociais compreendidas como estáveis e eternas. A segunda é considerada uma fase líquida, pois na contemporaneidade tais organizações e relações não conseguem manter uma forma por muito tempo; decompõem-se e dissolvem-se mais rápido que o tempo que levam para serem construídas.

No viés da mobilidade e da flexibilidade, Bauman (2001) debate as temáticas do mercado de trabalho. Em linhas gerais, a crença no trabalho a "longo prazo" cedeu lugar à concepção de trabalho a "curto prazo". Segundo o autor, na modernidade sólida, um jovem aprendiz que tivesse seu primeiro emprego numa fábrica terminaria sua vida profissional no mesmo lugar. No cenário flexível da contemporaneidade, "[...] um jovem americano com nível médio de educação espera mudar de emprego 11 (onze) vezes durante sua vida de trabalho" (p. 169).

As configurações do trabalho contemporâneo parecem ter tomado forma líquida, ao se reestruturarem a partir da substituição dos padrões produtivos tradicionais, associados principalmente ao taylorismo e ao fordismo, por um novo padrão, que prioriza os aspectos da flexibilidade e que se caracteriza, basicamente, pelo vínculo de trabalho temporário. A flexibilização também pode ser compreendida como uma maneira de fragilizar os direitos sociais trabalhistas, pois há uma transferência de riscos e custos para o trabalhador, acarretando, entre outros, o aumento das jornadas de trabalho e a precarização das condições do mesmo (HARVEY, 2000).

As peculiaridades atuais do mundo do trabalho percorreram um caminho que nem sempre se configurou como flexível. As principais transformações ocorreram, especificamente, nas últimas décadas do século XX, mediante alterações no modo de produção e reprodução capitalista. A evolução tecnológica, a automação e a robótica marcaram esse período, estabelecendo novas formas de relacionamento entre trabalho e trabalhador. Para Coutinho (2009), apesar do novo formato, a lógica do regime capitalista de acumulação continua presente na contemporaneidade, afetando, inclusive, as formas de ser dos sujeitos no contexto produtivo.

Do fordismo à uberização, as relações de trabalho ganharam novos contornos, não só para os trabalhadores manufatureiros, mas para todos que vendem sua força de trabalho, incluindo "[...] o enorme leque de trabalhadores precarizados, terceirizados, 
fabris e de serviços, part time ${ }^{3}$, que se caracteriza pelo vínculo de trabalho temporário, em expansão no mundo produtivo" (ANTUNES, 2006, p. 218).

A principal característica do Fordismo e do Taylorismo é a produção em massa, mediante uma linha de montagem para gerar produtos mais homogêneos. Neste modelo, há uma fragmentação das funções. Uma separação entre aquele que elabora e aquele que executa a produção.

Os modelos de produção citados são interpretados por Marsden (2004) como uma forma dualista de organização dos trabalhadores, ou seja, têm-se de um lado aqueles cargos responsáveis pelas tarefas de concepção e, do outro lado, os trabalhadores incumbidos da execução da tarefa.

Posteriormente, os modos de produção se incorporaram ao denominado Toyotismo, em que a principal característica é produzir de acordo com a demanda, numa tentativa de redução de estoques e diversificação de produtos. A ordem é o aproveitamento total da produção e a reposição de estoques somente após a venda. Neste modelo, o trabalhador ideal é o polivalente, ou seja, aquele que consegue assumir várias funções dentro de um único processo. No Toyotismo, os aspectos de flexibilização e de terceirização começam a aparecer (ANTUNES, 2006).

$\mathrm{Na}$ direção da flexibilização, Pochmann (2010) chama a atenção para as concepções gerenciais e organizacionais e os novos tipos de trabalho, os quais não exigem tempo nem locais fixos. Neste sentido, estabelece diferenças entre trabalho material e imaterial. O primeiro é aquele "[...] cujo esforço físico e mental resulta em alguma coisa física, concreta, tangível, palpável” (p. 32). No segundo, o resultado físico do trabalho não pode ser identificável e sua realização pode ocorrer em qualquer horário e local.

Vale ressaltar, que essa extensão da jornada de trabalho, para além do local de serviço, acaba por afetar alguns direitos trabalhistas como, por exemplo, o aparecimento de doenças decorrentes da atividade profissional, mas que se manifestam fora do ambiente de trabalho e, por isso, não são consideradas como doenças ocupacionais. Do mesmo modo, as horas extras realizadas fora do expediente, em atividades como responder a um e-mail do coordenador no dia de folga, na maioria das vezes, não são computadas e remuneradas. Questões da vida pessoal também são comprometidas, pois há que se considerar que esse modelo de trabalho acaba exigindo uma conexão constante, acarretando um aumento da jornada de trabalho e afetando a qualidade de vida dos trabalhadores. "Estamos vivendo uma situação de estarmos quase 'plugados' vinte e quatro horas no trabalho. Adeus final de semana com a família, com esporte" (POCHMANN, 2010, p. 34).

Outra formatação para produção e comercialização de bens e serviços é a denominada Divisão Internacional do Trabalho. Trata-se de uma divisão geográfica de atividades e serviços entre países, como estratégia para a redução de custos da produção. Na maioria das vezes, essa configuração acontece quando um país oferece matéria-prima, mão de obra barata e benefícios para instalação de empresas (isenção de impostos) ao país investidor e detentor da tecnologia produtiva.

Nessa direção, Pochmann (2015) adverte que essa formatação pode acarretar uma divisão desigual do trabalho, separando aqueles que criam daqueles que executam. Assim, os países que detém o investimento em pesquisas para desenvolvimento de novas tecnologias apropriam-se do poder de criação e planejamento e,

\footnotetext{
${ }^{3}$ Trabalhadores que são contratados esporadicamente para dias ou horários específicos, sem estabelecer vínculos trabalhistas. Ele se difere do trabalhador Full Time, aquele no qual o indivíduo trabalha em tempo integral em uma instituição, podendo estabelecer vínculos formais de trabalho, garantindo direitos e criando possibilidades de prosseguimento de carreira.
} 
consequentemente, dos maiores salários. Por outro lado, o processo de produção e execução é deslocado para países mais pobres economicamente, demandando ocupações mais simples (tecnicamente) e mais rotineiras e, consequentemente, salários mais baixos.

No mesmo viés da flexibilidade e da divisão internacional do trabalho, o conceito de Uberização vem sendo utilizado para definir novos modelos do trabalho contemporâneo. Vale ressaltar que essa terminologia não foi encontrada nas publicações acadêmicas que abordam a temática, mas sim, em blogs ${ }^{4}$ e veículos de comunicação ${ }^{5}$ que elaboram artigos sobre negócios, mercado financeiro, recursos humanos e mundo corporativo. Esse termo foi inspirado na empresa Uber ${ }^{6}$, assim como o Fordismo foi inspirado pela empresa Ford e o Toyotismo, pela montadora de veículos Toyota.

Da configuração das empresas, passando pelas formas de controle ao gerenciamento e expropriação do trabalho, temos uma forma de regulação dos modos de produção, em que uma instituição, através de softwares e aplicativos, conecta o sujeito disposto a vender sua mão de obra ao público consumidor. O trabalhador, neste caso, apesar de ser autônomo, está submetido às regras administrativas e produtivas superiores.

Esse trabalho just-in-time é conhecido como "Contrato Zero Hora" e os trabalhadores recebem a denominação de ultraflexíveis. Estes são contratados para exercerem suas funções de acordo com a demanda e as necessidades da empresa, ou seja, ficam à disposição, porém, só recebem pelas horas efetivamente trabalhadas. De acordo com Sahuquillo (2015), esse modelo teve início em 2008, diante da crise financeira no Reino Unido. Como forma de ilustrar essa configuração ultraflexível, a autora descreve a seguinte cena:

É hora do almoço e, sentado em um banco perto das docas de Liverpool, Clive abocanha os últimos pedaços de seu sanduíche de frango caseiro. $\mathrm{Na}$ realidade, não tem pressa. Hoje, sua pausa para a refeição é extremamente longa. "Quatro horas! O chefe me disse que não precisa de mim durante este intervalo, mas que mais tarde terei outro par de horas de trabalho", explica, enquanto limpa as mãos em um pedaço de papel. Afirma que para ele não compensa voltar para casa, e que pretende passar o resto do tempo livre assistindo a corridas de cavalo na pequena casa de apostas Paddy Power. Há um ano, muitos dos dias são imprevisíveis assim para este homem de 46 anos, cabelo ralo e olhos pequenos e vivos. Trabalha em uma distribuidora com um "contrato de zero horas", uma modalidade na qual o empregador não garante ao trabalhador um mínimo de horas de carga por mês e, portanto, tampouco um salário mínimo (p. 1, grifo nosso).

Percebe-se que essa nova formatação do mundo do trabalho vai além das questões de vínculos empregatícios e direitos trabalhistas. Outras dimensões da vida, como a família e o lazer, também são afetadas. No trecho acima, por exemplo, o empregado

\footnotetext{
${ }^{4}$ O Blog Passa Palavra, em fevereiro de 2017, publicou uma reflexão sobre essa temática que encontra-se disponível pelo seguinte endereço eletrônico: 〈http://passapalavra.info/2017/02/110685>. Acesso em 02 maio 2019.

${ }^{5}$ Um dos exemplos de veículo de comunicação que adotou tal terminologia foi a revista EXAME, que fez uma reportagem específica sobre o assunto. Disponível em: $<$ https://exame.abril.com.br/\%20negocios/mao-de-obra-sofreu-uberizacao/>. Acesso em 01 maio 2019. 6 A Uber é uma empresa de tecnologia fundada em 2009 nos EUA e que chegou ao Brasil em 2016. Através de um aplicativo, oferece serviço de transporte de passageiros, sendo que os motoristas prestadores do serviço são cadastrados e devem seguir determinadas regras e padrões. Além disso, os trabalhadores registrados devem destinar um percentual do que for arrecadado com as viagens conseguidas através do aplicativo para a empresa.
} 
Clive aproveita o "tempo disponível" para assistir corridas de cavalo, mas isso só foi possível, pois ele havia sido informado de que voltaria ao trabalho no final do dia. Porém, outras pessoas não sabem sequer a escala do dia, nem da semana e muito menos a escala do mês em que deverão estar presentes para realizar suas funções, ficando assim, reféns das incertezas, o que afeta seu planejamento do tempo livre. Para Antunes (2006), as transformações no mundo do trabalho contemporâneo não repercutiram somente na materialidade dos trabalhadores, mas também na subjetividade dos sujeitos, ou seja, "[...] na sua forma de ser" (p. 23).

Sennett (2009) corrobora a ideia de que são significativos os impactos dessa flexibilização na vida das pessoas, afirmando que o caráter pessoal sofre consequências dessa nova configuração. Afinal, a incerteza provocada pela flexibilidade causa ansiedade, pois "[...] as pessoas não sabem que riscos serão compensados e que caminhos seguir" (p. 9). Vale ressaltar, que esse modelo flexível pode passar uma falsa ideia de liberdade, pois "[...] a nova ordem impõe novos controles, em vez de simplesmente abolir as regras do passado" (SENNETT, 2009, p. 10).

Com tantas mudanças ocorrendo em velocidade recorde, Sennett (2009) chama a atenção para o perfil profissional que se espera destes "novos" trabalhadores. Para o autor, é preciso que estes possuam qualidades como: agilidade, flexibilidade e capacidade de adaptação às mudanças, já que as relações estabelecidas com o mercado serão de curto prazo.

As narrativas dos autores abordados se convergem na apresentação de um novo modelo de mercado de trabalho. Um trabalho contemporâneo, margeado por questões econômicas e tecnológicas que acabam por reorganizar os sistemas de produção e a forma dos sujeitos se relacionarem com o tempo e com o espaço de trabalho. No entanto, é preciso perguntar se essas relações ocupacionais apresentadas se aplicam a todos os trabalhadores. No caso específico desse artigo, procuramos estabelecer relações entre formação e atuação profissional em lazer com as características do mercado de trabalho contemporâneo.

\section{FORMAÇÃO E ATUAÇÃO PROFISSIONAL EM LAZER NO VIÉS DA CONTEMPORANEIDADE}

O campo de atuação profissional em lazer pode ser caracterizado a partir de duas dimensões: dos setores da sociedade e dos vínculos empregatícios. Essas dimensões, apesar de relacionarem-se entre si, serão abordadas de forma separada, para uma melhor compreensão.

Em relação à primeira dimensão, de acordo com a Constituição Federal (BRASIL, 1988), nossa sociedade está dividida em três setores: o primeiro setor, também denominado de setor público, é representado pelo Estado; o segundo setor é representado pelas instituições privadas e o terceiro setor abriga as associações e entidades sem fins lucrativos. Todos estes três setores são espaços possíveis de atuação para aqueles que desenvolvem atividades profissionais no campo do lazer.

No primeiro setor estão as instituições públicas da esfera Municipal, Estadual e Federal que oferecem vivências de lazer para a população, através de ações de políticas públicas. O Programa Esporte e Lazer na Cidade (PELC) ${ }^{7}$, por exemplo, é uma dessas

\footnotetext{
7 “O Programa Esporte e lazer da Cidade (PELC), desenvolvido por intermédio da Secretaria Nacional de Esporte, Educação, Lazer e Inclusão Social (Snelis), proporciona a prática de atividades físicas, culturais e de lazer que envolvem todas as faixas etárias e pessoas com deficiência, estimula a convivência social, a formação de gestores e lideranças comunitárias, favorece a pesquisa e a socialização do conhecimento, contribuindo para que o esporte e lazer sejam tratados como políticas e direitos de todos" (MINISTÉRIO
} 
políticas públicas que abriga profissionais que trabalham no campo do lazer. No setor privado estão as empresas que vendem serviços ou produtos visando lucros. As possibilidades de atuação neste âmbito variam entre hotéis, parques temáticos, clubes, empresas de eventos, campings, cruzeiros marítimos, dentre outros. Inclui-se, também, neste segundo campo, as entidades patronais como o Serviços Social do Comércio (SESC) e Serviço Social da Indústria (SESI). O terceiro setor, diz respeito às entidades organizadas pela sociedade civil, de acordo com suas necessidades. Este campo é constituído, por exemplo, por Organizações Não Governamentais (ONGs) e Associações de classes. Para que estes setores ofertem atividades de lazer, é preciso que contem com profissionais que elaborem, coordenem, executem e avaliem tais vivências.

No que diz respeito à segunda dimensão, quando inseridos nesses setores, os vínculos empregatícios com os profissionais se estabelecem de diferentes formas: freelancer - contratação esporádica sem vínculos empregatícios; concursado - cargo permanente no setor público; formal - prestação de serviço com vínculos empregatícios; autônomo - prestação de serviço independente, sem vínculos empregatícios; terceirizado - composição do quadro de prestadores de serviço, possuindo ou não vínculos empregatícios.

Werneck (2001), Melo e Alves Júnior (2003) e Stoppa e Isayama (2001) corroboram o pensamento de que o mercado informal acaba por abarcar parte das pessoas que trabalham no campo do lazer. Afinal, a inexistência de vínculo empregatício é uma opção considerada viável para pequenas empresas, ou para aquelas que só contratam trabalhadores temporários, como "[...] hotéis em período de alta temporada, pois grandes empresas não têm como escapar dos encargos trabalhistas quando necessitam de empregados atuantes em todo ano, e não apenas em determinadas épocas" (WERNECK, 2001, p. 39).

Apesar de existirem ações de lazer permanentes, que não se limitam aos finais de semana, férias e feriados, o caráter sazonal do lazer pode interferir no processo de contratação de profissionais para atuarem nesse campo. Dessa forma, as oportunidades de trabalho podem assumir o modelo just-in-time que, como vimos, obriga que os profissionais desenvolvam suas funções apenas quando são convocados, ficando assim, à mercê da demanda do mercado.

Outro ponto a ser destacado diz respeito às peculiaridades da formação e atuação no âmbito do lazer, afinal trata-se de um espaço que possibilita a atuação de profissionais com diferentes formações (turismólogos, profissionais de educação física, pedagogos, arte educadores, dentre outros) e, por outro lado, têm-se a atuação de profissionais com formação específica em lazer e formados em diferentes níveis: nas instituições de ensino técnico, graduação e pós-graduação. Neste ponto, consideramos importante a interdisciplinaridade, uma vez que se trata de um fenômeno que necessita de uma correlação de competências, saberes e habilidades específicas de diferentes áreas, no intuito de contemplar os variados interesses culturais vivenciados no lazer.

Vale lembrar que para atuar no campo do lazer não é exigida, legalmente, nenhuma formação específica. A única indicação que se tem é a da Classificação Brasileira de Ocupações $(\mathrm{CBO})^{8}$, que propõe que para atuar no campo do lazer a

DOS ESPORTES, 2017). Disponível em: <http://www.esporte.gov.br/index.php/institucional/esporteeducacao-lazer-e-inclusao-social/esporte-e-lazer-da-cidade/programa-esporte-e-lazer-da-cidade-pelc>. Acesso em: 01 jun. 2018.

${ }^{8}$ A Classificação Brasileira de Ocupações - CBO, instituída por portaria ministerial no ${ }^{\text {. }} 397$, de 9 de outubro de 2002, tem por finalidade a identificação das ocupações no mercado de trabalho, para fins classificatórios junto aos registros administrativos e domiciliares. Informação retirada do site: <www.mtecbo.gov.br>. Acesso em: 05 abr. 2019. 
escolaridade mínima deva ser ensino médio. Não obstante, ainda é recorrente a ideia de que para atuar nessa área não é preciso formação, basta ter um dom. Neste sentido, a formação torna-se dispensável, pois outras características como, extroversão, beleza e carisma são mais valorizadas (STOPPA, 2001).

Diante do exposto, atuam no âmbito do lazer os seguintes perfis: pessoas sem formação acadêmica, profissionais com formação acadêmica específica em lazer e profissionais com formação acadêmica em diferentes cursos. Acreditamos na importância da formação acadêmica para o profissional que atua no âmbito do lazer, afinal, as atribuições deste não se resumem à execução de tarefas ou à concretização de uma programação pré-estabelecida.

Entendemos que esse profissional pode assumir, também, as funções de planejamento, organização, coordenação, supervisão e avaliação de vivências e projetos de lazer. Para tanto, demanda-se competência técnica, sensibilidade e compromisso político como embasamento de uma intervenção crítica na busca da emancipação dos sujeitos envolvidos. No entanto, não quer dizer que para assumir essa postura seja obrigatória uma formação acadêmica.

Afinal, não podemos desconsiderar os saberes de experiência ${ }^{9}$; ao contrário, é preciso reconhecer que a importância da experiência profissional e das vivências pessoais para uma atuação no campo do lazer. No entanto, considerá-las por si só, não basta. Consideramos os saberes acadêmicos e os conhecimentos científicos como uma possibilidade de sair da atuação centrada no senso comum, pois, uma vez fundamentados, permitem ao profissional encontrar brechas para intervir no campo do lazer, entendendo-o como um fenômeno amplo e complexo.

Freidson (1996) estabelece uma relação entre profissão/ofício e leigos/diplomados, diferenciando-os em relação ao tipo de conhecimento e de habilidade que são requisitados e ao grau de complexidade exigido para atuar. Para este autor, todas as pessoas possuem conhecimento sobre algo, ou seja, em qualquer lugar pode ser localizado o conjunto de saberes de um povo. Pode-se encontrar saberes comuns a todos (senso comum), como também conhecimentos especializados que estão disponíveis apenas para um grupo específico de pessoas (saber científico). Assim, as profissões se distinguem dos ofícios por serem uma "[...] especialização criteriosa teoricamente fundamentada" (FREIDSON, 1996, p. 142).

Essa "especialização criteriosa" é definida por Freidson (1996) como um trabalho que não pode ser exercido mecanicamente, uma vez que os profissionais têm que dominar o conhecimento para adaptá-lo de acordo com cada situação. Esse modelo difere da chamada "especialização mecânica", em que os profissionais responsáveis pela execução de determinadas tarefas desenvolvem ações simples, de caráter invariável e repetitivo. Ainda sobre a relação especialização criteriosa versus mecânica, o autor considera que a primeira é aprendida através do ensino formal, de modo que o ensino e a pesquisa legitimam a profissão e a segunda, a especialização mecânica, é aprendida através do fazer no próprio local de trabalho.

Por entendermos o campo do lazer como uma profissão e não como um ofício, concordamos com a abordagem de Freidson (1996), que denomina de "trabalho especializado" uma profissão que não pode ser realizada mecanicamente. Essa natureza de trabalho é calcada em tarefas complexas que variam de acordo com diferentes circunstâncias, exigindo que o trabalhador mobilize seus conhecimentos e habilidades, de acordo com cada situação, para obter sucesso.

\footnotetext{
${ }^{9}$ Tardif (2002) considera saberes da experiência aqueles provenientes da prática e do fazer cotidiano, influenciados pela trajetória de vida pessoal e social.
} 
Dessa forma, vale reconhecer que um novo perfil profissional tem sido exigido para lidar com os princípios da rapidez, da flexibilidade e da qualidade, distanciando-se daquele perfil mecânico, calcado apenas pela reprodução e execução de tarefas. Tornase importante uma formação voltada para habilitar um profissional capaz de lidar, simultaneamente, com diferentes fatores. Gondim (2008) afirma que tais habilidades devem reunir questões cognitivas, técnicas e atitudinais e explica tais conceitos:

\begin{abstract}
Cognitivas: comumente obtidas no processo de educação formal (raciocínio lógico e abstrato; resolução de problemas, criatividade, capacidade de compreensão, julgamento crítico e conhecimento geral); Técnicas especializadas: informática, língua estrangeira, operação de equipamentos e processos de trabalho; Comportamentais e Atitudinais: cooperação, iniciativa, empreendedorismo (como traço psicológico e como a habilidade pessoal de gerar rendas alternativas que não as oferecidas pelo mercado formal de trabalho), motivação, responsabilidade, participação, disciplina, ética e a atitude permanente de aprender a aprender (p. 300).
\end{abstract}

Destacamos, portanto, que o perfil profissional transcende os aspectos técnicos, valorizando, também, aspectos intelectuais e de comportamento. Portanto, um profissional deve reunir competências suficientes não só para executar, como também para criar (PERRENOUD, 2002). Para que isso se efetive, o profissional deve mobilizar conhecimentos, habilidades e atitudes para decidir e agir de acordo com cada situação. Em se tratando de um mercado flexível, em constantes mudanças, é difícil o trabalhador prever a situação problema sobre a qual deverá intervir, para tanto, deve reunir saberes científicos e saberes advindos das experiências pessoais e profissionais.

Neste contexto, fazem-se necessárias reflexões sobre os processos de formação profissional, na tentativa de entender como as habilidades e competências profissionais têm sido abordadas e, consequentemente, qual perfil profissional tem sido proposto pelo mercado. Afinal, como alerta Gondim (2008), a educação formal vem se preocupando em estabelecer um equilíbrio entre os aspectos cognitivos, técnicos e atitudinais, na tentativa de atender tanto às expectativas do mercado de trabalho, quanto de oferecer uma formação crítica e autônoma, que possibilite aos profissionais questionar a lógica do mercado.

Em relação ao lazer, autores como Marcellino (2010) e Isayama (2010) sinalizam a importância de superar a formação profissional para além dos conhecimentos técnicos. Neste sentido, Perrenoud lembra que situações complexas exigem mais que um repertório de receitas, "[...] exigem um procedimento de resolução de problemas, uma forma de invenção" (PERRENOUD, 2002, p. 11), ou seja, é necessário que os profissionais saibam mobilizar os conhecimentos de acordo com cada situação que surgirá no desenvolvimento de sua intervenção.

Porém, para entender o processo de formação profissional em lazer, é necessário reconhecer pontos importantes como as características do campo de atuação, bem como as funções desenvolvidas no mercado de trabalho. É preciso contextualizar que os profissionais que atuam no campo do lazer estão inseridos na $\mathrm{CBO}$, desde o ano de 2002, sob a categoria de recreadores, no código 3714-10. De acordo com a CBO, essa categoria corresponde também a outras denominações como: Gentil Organizador, Monitor de entretenimento, Monitor de esportes e lazer, Monitor de recreação, Monitor infantil e Recreacionista. Para a categoria em questão, é destacada a seguinte descrição ocupacional: 
Trabalham em instituições de ensino, de atividades recreativas, culturais e desportivas, em empresas de atividades de lazer, hotéis, acampamentos, resorts, clubes, acantonamentos, navios, festas e eventos, parques temáticos, bufês infantis, excursões, colônias de férias e spas. Geralmente são autônomos, organizam-se em equipe de recreadores; desenvolvem as atividades sob supervisão ocasional, em ambientes fechados, a céu aberto e em veículos, atuando em horários irregulares (MTE, 2002, n.p.).

Além disso, de acordo com a CBO, cabem a estes profissionais as seguintes funções: promover atividades recreativas, visando o entretenimento, a integração social e o desenvolvimento pessoal dos clientes; elaborar e executar projetos de atividades recreativas, promovendo o lúdico e estimulando a participação; atender clientes e coordenar setores de recreação; administrar equipamentos e materiais para recreação.

Nozoe, Bianchi e Rondet (2003) abordam os níveis de escolaridade das pessoas que trabalham nesse segmento e consideram que:

\footnotetext{
Apesar de existirem alguns cursos na área - desde cursos técnicos pertencentes ao sistema SENAI/SENAC até cursos de graduação em Gestão de Lazer e Eventos-, a maioria dos profissionais não possui formação específica. Nesse sentido, seu nível de escolaridade varia muito, indo desde o segundo grau incompleto até o nível superior, este nem sempre na área específica (p. 9).
}

Ainda assim, não é raro encontrar espaços de formação que privilegiam a prática em detrimento da fundamentação teórica ou que desvinculam prática e teoria, encarando-as de uma forma dicotomizada. Segundo Marcellino (2010), ao desconhecer a teoria que fundamenta sua intervenção, o profissional, além de confundir a prática do lazer com a prática que o lazer requer, não estabelece uma prática, e sim, um tarefismo. Segundo o autor, é preciso romper conceitos do senso comum que acabam por atribuir à teoria o sentido de algo vazio, desvinculado-a da realidade; e à prática, a noção de tarefa desprovida de sentido.

Isayama (2010) diz ainda que é preciso superar a tendência de relacionar as práticas com a recreação e as teorias com lazer e complementa: "[...] um sólido referencial teórico possibilita a compreensão da prática por meio de novos olhares, permitindo a consolidação da práxis" (p. 12). A práxis é aqui entendida como a dialética entre teoria e prática, sem que uma se sobressaia sobre a outra, como sugere Sánchez Vázquez (1977): "Não há práxis como atividade puramente material, isto é, sem a produção de finalidades e conhecimentos que caracterizam a atividade teórica" (p. 208).

Dessa forma, é indispensável uma sólida formação comprometida com os embasamentos teórico-práticos, estabelecendo laços com a pesquisa e com a formação cultural dos sujeitos. Só assim, teremos profissionais capazes de perceber "[...] os pontos de interseção entre a problemática do lazer e as demais dimensões da ação humana" (MARCELLINO, 1995, p. 21).

Da mesma forma, não acreditamos que o processo formativo deva desconsiderar os componentes técnicos. Aprender, vivenciar e dominar os conteúdos que compõem a profissão é de suma importância, assim como o domínio do conhecimento científico, por isso o equilíbrio entre um e outro se faz necessário. Nesse sentido, corroboramos com os pensamentos de Kuenzer (2004), quando afirma que a atuação competente só será possível se houver paridade entre as dimensões técnica e científica.

Nesse contexto, os estudos de Schön (2000), apesar de serem voltados para a formação docente, podem contribuir com as análises sobre a formação profissional no campo do lazer. $\mathrm{O}$ autor propõe uma formação profissional que articule teoria e prática, 
baseada no processo de reflexão-na-ação, que privilegia o ensino, por intermédio do fazer da própria profissão; e a reflexão, pela interação do profissional e o sujeito.

Schön (2000) considera que o profissional se depara com diferentes desafios no decorrer de sua trajetória, sendo alguns mais simples e outros de complexidade caótica e confusa. $\mathrm{O}$ autor critica uma formação profissional fundamentada na solução de problemas de forma instrumental e que valoriza apenas estratégias técnicas para propósitos específicos. A esse processo de formação, Schön (2000) denomina "racionalidade técnica", porque basta o profissional lançar mão de seus conhecimentos técnicos e científicos para solucionar alguma tarefa. Isso não acontece de forma tão linear, uma vez que o profissional tende a encontrar, na sua atuação, situações complexas o suficiente, que exigem mais do que simples técnicas para solucioná-las, ou seja, "[...] quando um profissional reconhece uma situação como única, não pode lidar apenas aplicando técnicas derivadas de sua bagagem de conhecimento profissional" ( $\mathrm{p}$. 16).

Além do mais, Schön (2000) afirma que as instituições de ensino profissional estão baseadas na racionalidade técnica, pois apresentam currículos que hierarquizam o conhecimento: a ciência básica, seguida pela ciência aplicada e, por último, as habilidades técnicas vinculadas à prática do cotidiano.

Acreditamos que a formação profissional deve buscar a unidade entre teoria e prática, dialogando com a realidade do campo de atuação. Dessa forma, não se pode valorizar determinado conhecimento em detrimento do outro, visto que, no processo da intervenção profissional, a formação prática não estará desvinculada da formação teórica. Neste sentido, concordamos com o pensamento de Perez Gomez (1992), que aborda a construção do saber profissional sem desvincular teoria.

Tardiff (2008) também contribui para a reflexão sobre a relação entre a ciência e as habilidades técnicas, ao refletir que "[...] é a profissão que deve servir de base à formação e não, por exemplo, as disciplinas, os módulos ou os campos de conhecimento" (p. 31). O autor investigou um programa de formação ${ }^{10}$ no qual um dos princípios é a formação baseada na profissão. Nesse caso, o foco do programa é a ação profissional em si, "[...] simultaneamente como objeto de conhecimentos, como espaço de ação e de formação, como mecanismo de reflexão teórica, cultura e crítica" (TARDIFF, 2008, p. 31). No caso da formação profissional em lazer, esta ocorreria nos espaços de formação, nas vivências de lazer e nos processos de intervenção. Certamente, essa proposta se aproxima da ideia do profissional reflexivo de Schön (2000), que propõe a unidade entre teoria e prática, privilegiando a reflexão-na-ação.

Tardiff (2008) chama a atenção para os desafios da proposta de formação baseada na profissão, tendo em vista que, ao ensinar pelo exercício da profissão, lidamos com determinada realidade. Dessa forma, é preciso pensar acerca da realidade, a fim de que os profissionais tenham conhecimentos para intervir.

Neste sentido, calcar a formação apenas pelo viés prático é um equívoco, uma vez que os campos de atuação profissional são dinâmicos. Isso significa dizer que uma sólida formação teórica permite identificar as configurações do exercício da profissão, permitindo a revisão e a construção de saberes. Por outro lado, fundamentar o processo formativo apenas em questões teóricas pode acabar tornando os saberes profissionais abstratos, distantes da realidade do mercado.

\footnotetext{
${ }^{10}$ Haute Ecole Pédagogique (HEP) - Suíça é uma universidade profissional que se dedica à pesquisa sobre o ensino e a formação docente. Desde 2005, a HEP começou a fazer reformas importantes nos seus programas de formação de docentes de $1^{\circ}$ e $2^{\circ}$ anos, baseadas na articulação entre teoria e prática, na perspectiva da reflexão na ação, proposta por Shön (2000).
} 
Trazendo essas reflexões para o âmbito do lazer, apoiamos na argumentação de Isayama (2010), que considera que as transformações necessárias nas vivências de lazer presentes no mercado só ocorrerão a partir do momento em que a teoria for pensada, formulada e aplicada com base na realidade daqueles que atuam no âmbito do lazer.

Outro ponto pertinente diz respeito à importância da pesquisa no processo de formação do profissional do lazer. Concordamos com Gomes (2010), quando afirma que a pesquisa se configura como a mola propulsora do processo do conhecimento, compreendendo-a "[...] como uma construção intelectual, salientando sua relevância para despertar uma atitude mais curiosa, indagadora e crítica por parte do profissional do lazer" (p. 87).

A pesquisa incentiva os profissionais a examinarem suas próprias ações, a partir da necessidade de melhor compreender a natureza dos dilemas que emergem do processo de atuação profissional. A partir da constatação da realidade, é possível transformar e adequar a intervenção de acordo com o cenário que se apresenta. Como vimos, estamos vivendo um momento líquido, marcado por incertezas, o que torna necessário rever constantemente as formas de lidar com as variáveis que se apresentam no mercado de trabalho. Concordamos com Enricone (2008), que afirma que os profissionais se beneficiam com as pesquisas quando "[...] refletem a respeito do seu próprio processo e modificam seu agir a partir de novas conclusões" (p. 82).

Portanto, as possibilidades de formação no campo do lazer precisam romper com a dicotomia teoria e prática e que a pesquisa é uma ação que deve permear todo o processo de formação. Assim, é possível refletir sobre a ação e estabelecer uma visão de totalidade no que se refere à formação dos animadores culturais, respeitando as práticas educativas cotidianas e as possibilidades de pesquisa no campo.

A formação cultural dos profissionais do lazer é mais um tema importante no processo de formação profissional, pois, assim como Melo (2010), concebemos que um profissional que intervém no plano cultural deve possuir sua própria bagagem cultural.

Entendemos que é preciso ampliar as oportunidades de vivências culturais, variando as diferentes formas de linguagem (cinema, teatro, música), na busca da sensibilização dos profissionais do lazer e, como diria Melo (2010, p. 134) "[...] para sensibilizar os alunos para uma atuação diferenciada, não basta apenas falar sobre o processo de animação cultural", é preciso estimulá-los a ampliar seu repertório cultural de vivências.

O lazer deve ser entendido no interior dos espaços de formação como uma “[...] prática cultural que possui uma política e uma pedagogia; uma prática cultural que ensina e forma; uma prática cultural que governa condutas e produz sujeitos de determinados tipos" (PARAÍSO, 2010, p. 30). De acordo com a autora, não podemos desconsiderar que, na contemporaneidade, os currículos escolares ${ }^{11}$ estão concorrendo com outras "máquinas de ensinar" ${ }^{12 "}$ que precisam ser compreendidas e analisadas dentro de uma formação profissional no âmbito do lazer. Por essa razão:

Consideramos que artefatos culturais como a televisão, o cinema, o rádio, a
internet, as campanhas publicitárias, as revistas, os jornais, a literatura, os
jogos, os brinquedos, a dança, o teatro, a música etc. também são "máquinas
de ensinar", e possuem um currículo que precisa ser compreendido e
problematizado na formação, não somente daqueles que lidam com esses
próprios artefatos, mas, também, de todos os profissionais que lidam com a

\footnotetext{
${ }^{11}$ Paraíso (2010) classifica o currículo em escolar e não escolar. O primeiro representa aqueles presentes nas políticas curriculares das escolas, faculdades e universidades. Já o segundo, atravessa vários espaços e práticas (museus, internet, jogos, brincadeiras).

${ }^{12}$ Expressão criada por Giroux (1995) e adotada por Paraíso (2010).
} 
educação e com o lazer. Afinal, algumas dessas máquinas têm operacionalizado múltiplos deslocamentos por meio dos quais são divulgados e apreendidos outros saberes, outras habilidades, outros modos de viver e proceder e outras formas de afetividade. Esses saberes, modos de viver e proceder e essas habilidades e afetividades, muitas vezes, entram em conflito com aquilo que procuramos ensinar e divulgar por meio do currículo escolar ou universitário, em nossas lutas sociais e nos movimentos culturais dos quais participamos (PARAÍSO, 2010, p. 38).

A relação "máquina de ensinar" e lazer pode ser exemplificada pelo trabalho de Giroux (2005), que estabelece reflexões sobre o conhecimento construído/transmitido pelos filmes da empresa Walt Disney de entretenimento. A imagem de inocência, vinculada à empresa, camufla o poder "[...] institucional e ideológico de um conglomerado multinacional que exerce uma enorme influência social e política" (p. 137). Para este autor, os filmes podem assumir o papel de máquina de ensinar, a partir do momento em que produzem significados e padrões a serem seguidos, influenciando no processo formativo das pessoas.

Giroux (1995) entende que existe pedagogia em qualquer lugar no qual o conhecimento é construído e em "[...] qualquer lugar em que existe a possibilidade de traduzir a experiência e construir verdades" (p. 144). Por isso, reconhece que nas possibilidades de lazer também existe um currículo e, portanto, uma pedagogia que ensina.

Pensamos ser necessário que os profissionais que atuam no campo do lazer estejam atentos e olhem de forma crítica para as vivências no âmbito do lazer, para que um discurso ideológico não seja consumido de forma despercebida, mas que seja identificado, analisado e discutido. Para tanto, se faz necessária uma formação profissional diversificada e flexível, porém, comprometida com os aspectos técnicos e cognitivos articulados com a pesquisa e com a formação cultural.

\section{CONSIDERAÇÕES FINAIS}

O cenário apresentado neste texto aponta para um novo modelo de mercado de trabalho, permeado por questões econômicas e tecnológicas que reorganiza as relações entre trabalho e trabalhador. Os princípios da flexibilidade permeiam os campos de atuação que, por sua vez, solicitam um perfil profissional com capacidade de resolução de problemas e de adaptação às mudanças.

O perfil profissional almejado na contemporaneidade está distante de um modelo mecânico e engessado, calcado pela reprodução e execução de tarefas. Para tanto, acreditamos ser importante, uma formação voltada para habilitar profissionais capazes de mobilizar saberes diante das diferentes situações problemas que se apresentarão no decorrer do exercício da profissão. Concordamos com Gomes (2006) quando diz que os processos formativos em lazer devem privilegiar a associação entre "[...] conhecimentos, habilidades, procedimentos, valores e atitudes. O modelo de competências evidencia uma preocupação em superar ações e comportamentos limitados à padronização e à repetição, que se esgotam em si mesmas" (p. 4).

Diante das discussões que fundamentaram a compreensão sobre formação profissional, percebemos a necessidade de consolidar um processo formativo que busque a unidade entre teoria e prática, relacionada com a pesquisa e incentivando a ampliação da bagagem cultural. A aquisição de conhecimentos técnicos não é condição suficiente para atuar no campo do lazer. Há que se pensar num conjunto de competências que associe, além da capacidade técnica, a capacidade cognitiva e 
Carla Augusta Nogueira Lima e Santos; Hélder Ferreira Isayama

atitudinal, preparando o profissional para mobilizar seus saberes diante das diversas situações que atravessarão sua trajetória no mundo do trabalho.

\section{REFERÊNCIAS}

ANTUNES, R. Adeus ao trabalho?: ensaio sobre as metamorfoses e a centralidade do mundo do trabalho. 11. ed. São Paulo: Cortez; Campinas, SP: Editora da Universidade Estadual de Campinas, 2006.

BAUMAN, Z. Modernidade líquida. Tradução, Plínio Dentzien. Rio de Janeiro: Jorge Zahar, 2001.

BRASIL. Constituição da República Federativa do Brasil. Capítulo II, Art. $6^{\circ}$ de 05 de outubro de 1988. Brasília: Senado Federal, 1988.

COUTINHO. M. C. Sentidos do Trabalho Contemporâneo: as trajetórias identitárias como estratégia de investigação. Cadernos de Psicologia Social do Trabalho, v. 12, n. 2, p. 189-202, 2009.

ENRICONE, D. Trajetórias e memórias de constituição do campo da didática. In: ENCONTRO NACIONAL DE DIDÁTICA E PRÁTICA DE ENSINO (ENDIPE), 14., 2008, Porto Alegre. Anais... Porto Alegre: Ed. da PUC, 2008. p.77-88.

FREIDSON, E. Para uma análise comparada das profissões: a institucionalização do discurso e do conhecimento formais. Revista Brasileira de Ciências Sociais, v. 31, n. 11, p. 141-154, 1996.

GIROUX, H. A. "Memória e Pedagogia no Maravilhoso Mundo da Disney". In: SILVA, T. T. (Org.). Alienígenas na sala de aula: uma introdução aos estudos culturais em educação. 8. ed. Petrópolis, RJ: Vozes, 2005. p. 129-154.

GIROUX, H. A. Formação do professor como uma contra-esfera pública: a pedagogia radical como uma forma de política cultural. In: MOREIRA, A. F.; SILVA, T. T. (Orgs.). Currículo, cultura e sociedade. 2. ed. São Paulo: Cortez, 1995. p. 125-153.

GOMES, C. L. A contribuição da pesquisa para a formação profissional em lazer. In: ISAYAMA, H. F. (Org.). Lazer em estudo: currículo e formação profissional. Campinas: Papirus, 2010. p. 87-102.

GOMES, C. L. Competências Profissionais para a Formação em Recreação. In: CONGRESSO NACIONAL DE RECREACIÓN, 9., 2006, Bogotá. Memorias... Bogotá, D.C, Colombia: Coldeportes/FUNLIBRE, 2006. n.p.

GONDIM, S. M. G. Perfil Profissional e Mercado de Trabalho: relação com formação acadêmica pela perspectiva de estudantes. Estudos de Psicologia, v. 7, n. 2, p. 299-309, jul.-dez. 2008.

HARVEY, D. Condição pós-moderna: uma pesquisa sobre as origens da mudança cultural. São Paulo: Loyola, 2000.

ISAYAMA, H. F. Currículo e formação profissional em lazer. In: ISAYAMA, H. F. (Org.). Lazer em estudo: currículo e formação profissional. Campinas: Papirus, 2010. p. 59-86.

KUENZER, A. Z. Exclusão Includente e Inclusão Excludente: a nova forma de dualidade estrutural que objetiva as novas relações entre educação e trabalho. In: LOMBARDI, J. C.; SAVIANI, D.; SANFELICE, J. L. (Orgs.). Capitalismo, trabalho e educação. 2. ed. rev. Campinas: Autores Associados, HISTEDBR, 2004. p. 75-96.

MARCELLINO, N. C. A relação teoria e prática na formação profissional em lazer. In: ISAYAMA, Hélder Ferreira (Org.). Lazer em estudo: currículo e formação profissional. Campinas, SP: Papirus, 2010. p. 50-86.

MARCELLINO, N. C. (Org.). Lazer: formação e atuação profissional. Campinas: Papirus, 1995. 
MARSDEN, D. Sistemas de Emprego, Estratégias de Gestão e Instituições do Trabalho. Tempo Social. v. 16, n. 2, p. 225-255, 2004.

MELO, V. A. A Formação Cultural do Animador Cultural: antigas reflexões, persistências, continuidades. In: ISAYAMA, H. F. (Org.). Lazer em estudo: currículo e formação profissional. Campinas: Papirus, 2010. p. 127-142.

MELO, V. A.; ALVEZ JUNIOR, E. D. Introdução ao Lazer. São Paulo: Manole, 2003.

MINISTÉRIO DOS ESPORTES. Programa Esporte e Lazer da Cidade. Brasília: Ministério dos Esportes, 23 ago. 2017. Disponível em: <http://www.esporte.gov.br/index.php/institucional/esporteeducacao-lazer-e-inclusao-social/esporte-e-lazer-da-cidade/programa-esporte-e-lazer-da-cidade-pelc $>$.

Acesso em: 01 jun. 2018.

MTE/SPPE. Classificação Brasileira de Ocupações: CBO 2002. Brasília: TEM, 2002.

NOZOE, N. H.; BIANCHI, A. M.; RONDET, A. C. A. A nova Classificação Brasileira de Ocupações: anotações de uma pesquisa empírica. São Paulo em Perspectiva, São Paulo, v. 17, n. 3-4, p.234-246, 2003.

PARAÍSO, M. A. Currículo e formação profissional em lazer. In: ISAYAMA, H. F. (Org.). Lazer em estudo: currículo e formação profissional. Campinas: Papirus, 2010. p. 27-58.

PEREZ GOMEZ, A. O Pensamento Prático do Professor: a formação do professor como profissional reflexivo. In: NÓVOA, A. (Org.). Os Professores e a sua Formação. Lisboa: Dom Quixote, 1992. p. 1534.

PERRENOUD, P. A Prática Reflexiva no Ofício de Professor: profissionalização e razão pedagógica. Tradução, Cláudia Schilling. Porto Alegre: Artmed, 2002.

POCHMANN, M. O emprego na globalização: a nova divisão internacional do trabalho e os caminhos que o Brasil escolheu. São Paulo: Boitempo Editorial, 2015.

POCHMANN, M. A Atualidade da Categoria Trabalho na Sociedade de Reestruturação Produtiva. In: Conselho Federal de Psicologia. Psicologia crítica do trabalho na sociedade contemporânea. Brasília: CFP, 2010. p. 29-40.

SAHUQUILLO, M. R. Trabalhadores Ultraflexíveis. El País, Internacional, 3 maio 2015. Disponível em: <https://brasil.elpais.com/brasil/2015/05/01/internacional/1430504838_853098.html>. Acesso em: 01 maio 2018.

SCHÖN, D. A. Educando o profissional reflexivo: um novo design para o ensino e a aprendizagem. Tradução, Roberto Cataldo Costa. Porto Alegre: Artmed, 2000.

SENNETT, R. A Corrosão do caráter: as consequências pessoais do trabalho do novo capitalismo. Tradução, Marcos Santarrita. 14. ed. Rio de Janeiro: Record, 2009.

STOPPA, E. A. Lazer e mercado de trabalho. Licere, Belo Horizonte, v. 3, n. 1, p. 176-181, 2001.

STOPPA, Edmur Antonio.; ISAYAMA, Helder Ferreira. Lazer, mercado de trabalho e atuação profissional. In: WERNWCK, C. L. G.; STOPPA, E. A.; ISAYAMA, H. F. Lazer e mercado. Campinas: Papirus, 2001. p. 71-100.

TARDIF, M. Princípios para guiar a aplicação dos programas de formação inicial para o ensino. In: ENCONTRO NACIONAL DE DIDÁTICA E PRÁTICA DE ENSINO (ENDIPE), 14., 2008, Porto Alegre. Anais... Porto Alegre: Ed. da PUC, 2008. p.17-41.

TARDIF, M. Saberes docentes e formação profissional. Petrópolis: Vozes, 2002.

VÁZQUEZ, A. S. Filosofia da práxis. 2. ed. Rio de Janeiro: Paz e Terra, 1977. 
Carla Augusta Nogueira Lima e Santos; Hélder Ferreira Isayama

WERNECK, C. L. G. Lazer e mercado: panorama atual e implicações na sociedade brasileira. In: WERNECK, C. L. G.; STOPPA, E. A.; ISAYAMA, H. F. (Orgs.). Lazer e mercado. Campinas: Papirus, 2001. p. 13 - 44.

Recebido em: 23 jul. 2019.

Aprovado em: 26 ago. 2019. 